\title{
Optical Spectroscopic Determination of Hydrogen Isotopes in Aqueous Mixtures
}

\author{
Herbert P. Broida, Harold J. Morowitz, ${ }_{1}^{1}$ and Margaret Selgin
}

\begin{abstract}
Extension of the optical spectroscopic method of isotope analysis of gaseous mixtures of hydrogen and deuterium to mixtures of water and heavy water provides a direct method for determining the total water content of materials. A determination can be made on a sample of less than 0.1 milliliter in less than 10 minutes to an accuracy of a few percent. Using a sample of at least 1 milliliter, an accuracy of the order of 0.1 percent is obtained in an hour or less. This paper describes the system and the investigation of optimum operating conditions and effect of variations in operating conditions on precision and accuracy of measurement, as well as limitations of the technique. A sample of blood or serum can be measured directly almost as easily as one of distilled water. The optical spectroscopic method can be used to determine the water content of most materials, whether in the solid, liquid, or gas phase.
\end{abstract}

\section{Introduction}

Following initial work on an optical spectroscopic analysis of gaseous mixtures of hydrogen and deuterium $[1,2],{ }^{2}$ a similar technique was tried with mixtures of water and heavy water. A preliminary study [3] indicated that it was possible to carry out such analyses to an accuracy of better than 3 percent. The work discussed in the present paper represents an extension of the preliminary study in an effort to improve both the precision and the range and to determine present limitations of the analysis. A detailed study was made to determine the influence of operating variables on precision and accuracy of measurement in order to find the optimum operating conditions. In these studies the following accuracy was obtained: (a) 0.1 percent of the intensity ratio, in the isotope ratio range 0.01 to 1.0 ; (b) 1 percent, in the range 0.00015 to 0.01 (see table 5).

In addition to the above the rather practical problems of developing the method into a routine analytical technique were taken into consideration. For this reason efforts were made to achieve a rapid analysis, and operating conditions were viewed with the possibility of constructing a simple flow system and optical system for routine use. Several types of routine measurements were made concurrently with the study of the technique.

The technique used is as follows: The vapor from an aqueous sample containing a mixture of $\mathrm{H}_{2} \mathrm{O}$ and $\mathrm{D}_{2} \mathrm{O}$ is pumped through a tube where a high-frequency electrodeless discharge is maintained. The light emitted from the discharge tube contains lines of the Balmer series of hydrogen and deuterium with a very small amount of background radiation. The emitted light is dispersed by a monochromator, and the relative intensities of the $\beta$ lines of the Balmer series of hydrogen and deuterium are recorded and measured. The ratio of the intensities of the two

${ }_{1}^{1}$ Present address, National Heart Institute, National Institutes of Health, Bethesda, Md.

Figures in brackets indicate the literature references at the end of this paper. lines is a monotonic function of the relative concentration of the isotopes, and to a high degree of accuracy is equal to the ratio of the isotope concentrations. For precise work the measurement is a relative, rather than an absolute one, in that the relationship between intensity ratio and concentration ratio is obtained from calibration curves taken on standard samples whose compositions are determined by independent measurements.

The statistical terms $[4,5]$ used in this report are defined as follows: "Precision" refers to the variation encountered during readings taken in close succession under identical conditions. "Reproducibility" refers to the variation among readings when they are spread over a considerable time period. It is not a fixed quantity but depends somewhat on the time interval and the history of the apparatus in that interval. "Accuracy" refers to the variation of the measured concentration from the true value and is determined from the precision and reproducibility of the measurements and from the accuracy of the calibrated samples. The relationship between reproducibility and time determines how frequently it is necessary to take calibration points. These factors are all dependent on the stability of operating conditions.

The above variations are expressed either as standard deviation or as the coefficient of variation. These terms apply either for single measurements or for averages. As the standard deviation of the average is dependent on the number of readings taken, this value is most useful when compared to other sets of the same number of readings. For the purposes of this study, all standard deviations of the average refer to sets of 10 readings.

Stability of this system may be viewed in the following manner. Consider the measured ratio of intensities of the $\mathrm{D} \beta$ Balmer line to the $\mathrm{H} \beta \mathrm{Balmer}$ line at $4860.0 \mathrm{~A}$ and $4861.3 \mathrm{~A}$, respectively, and represent this ratio by $D_{1} / H_{1}$. This ratio is a function of a large number of variables such as the actual concentration ratio in the sample $\mathrm{D} / \mathrm{H}$, the tempera- 
ture, the pressure, the flow rate, etc., and may be represented in the following fashion:

$$
\mathrm{D}_{1} / \mathrm{H}_{1}=\mathrm{D} / \mathrm{H} f\left(\mathrm{D} / \mathrm{H}, X_{1}, X_{2} \ldots X_{n}\right),
$$

where $X_{1}$. . are independent variables. In practice, operating conditions are found such that $f$ is very nearly unity.

A completely stable set of operating conditions is one in which $\mathrm{D}_{1} / \mathrm{H}_{1}$ is a function of $\mathrm{D} / \mathrm{H}$ only, and is unaffected by small changes of $X_{1}, X_{2} \ldots X_{n}$. From a practical point of view, the conditions of stability are that changes of $\mathrm{D}_{\mathrm{i}} / \mathrm{H}_{1}$ due to variations of the $X$ 's are small compared with changes due to variations of $\mathrm{D} / \mathrm{H}$. . Many of the experimental curves shown in the following sections are graphs of the ratio $\mathrm{D}_{1} / \mathrm{H}_{1}$ as a function of one of the independent variables, with all other variables kept as constant as possible.

The samples employed in these experiments are in all cases aqueous solutions or suspensions in which the solvent is a mixture of hydrogen oxide, $\mathrm{H}_{2} \mathrm{O}$, and deuterium oxide, $\mathrm{D}_{2} \mathrm{O}$. The number used to describe concentrations is, unless otherwise specified, the atom ratio of deuterium to hydrogen, $\mathrm{D} / \mathrm{H}$. This figure depends only upon the number of atoms of hydrogen and deuterium in the sample and is independent of the equilibrium between $\mathrm{H}_{2} \mathrm{O}, \mathrm{HDO}$, and $\mathrm{D}_{2} \mathrm{O}$.

In taking measurements of isotope ratios the vapor is pumped from the liquid through the discharge tube. This procedure raises two questions; what is the relationship between $\mathrm{D} / \mathrm{H}$ in the liquid and the vapor and what fractionation (isotope separation) occurs in the flow process? The first question is purely academic with respect to the analysis of water. A given ratio of $\mathrm{D}$ to $\mathrm{H}$ in the liquid will always give rise to a reproducible ratio in the vapor, and as all measurements are taken relative to calibration samples, the measurement taken is, in all cases, referred back to the liquid.

Because of the difference in vapor pressure between $\mathrm{H}_{2} \mathrm{O}$, HDO, and $\mathrm{D}_{2} \mathrm{O}$, the process of evaporating liquid from samples involves some degree of fractional distillation. This has been investigated experimentally to study the over-all effect and will be discussed in a later section.

The processes occurring in the breakdown of water vapor in the radio-frequency field are imperfectly understood and will be discussed only briefly. The discharge through the water vapor in the tube causes excitation, ionization, and dissociation, giving rise to the following atoms and molecules from a mixture of normal and heavy water:

$$
\text { H, D, HD, } \mathrm{H}_{2}, \underset{2}{\mathrm{D}_{2}, \underset{\mathrm{D}_{2} \mathrm{O}}{\mathrm{OH}}, \mathrm{OD}, \mathrm{HDO}_{2},} \mathrm{O}_{2}, \mathrm{D}_{2} \mathrm{O}_{2}, \mathrm{H}_{2} \mathrm{O}, \mathrm{HDO} \text {, }
$$

as well as other groupings, most of which may exist as normal, excited, or ionized molecules. The emission spectrum from the discharge contains lines and bands from many of these components. The Balmer lines of hydrogen and deuterium are prominent in this spectrum.
The $\beta$ line of the Balmer series was chosen because the largest output signal was obtained for this line. This is a result of the product of the actual intensity and the phototube sensitivity being a maximum in the region of the $\beta$ Balmer line of the hydrogen spectrum. The $\alpha$ lines at $6561.0 \mathrm{~A}$ and $6562.8 \mathrm{~A}$ for $\mathrm{D}$ and $\mathrm{H}$, respectively, also can be used; this pair has the advantage of a somewhat larger separation than the $\beta$ pair. (1.8 A compared to $1.3 \mathrm{~A}$ ).

\section{Equipment}

\subsection{Glass Flow System}

A glass flow system was employed to provide a steady flow of sample vapor through the discharge tube. A flow system decreases problems of contamination by previous samples and simplifies the preparation of the sample for analysis. The system, shown photographically in figure 1 and schematically in figure 2 , consists of the following components:

1. Sample bottles. The sample bottles are equipped with an inverted standard taper ground-glass joint so that rapid change of samples can be made.

2. Sample connectors. The connectors are standard taper ground-glass joints corresponding to those on the bottles. A special vacuum line (fig. 2) provides a means of evacuating the air from the sample chamber before admitting sample into the main flow system.

3. Pressure regulator. In order to vary and control pressure in the discharge tube a parallel network is provided, consisting of a capillary and a continuously variable metal leak valve. In most of the studies described in this paper, the variable metal leak valve was used because fine pressure control and frequent adjustments were necessary. However, for routine measurements a fixed nonmetallic orifice is preferable.

4. Pressure gage. To measure pressure in the system, a pressure line connects through stopcocks to various critical locations. Pressure measurement is made by means of a commercial ionization gage, which utilizes alpha particles from a radium source to provide ionization. The gage can be used from pressures of $1 \mu$ to $1 \mathrm{~cm}$. Pressures used in this report are gage readings. Absolute pressure of water vapor is found by multiplying by 1.163 , the factor supplied by the gage manufacturer.

5. Discharge tube. The discharge tube consists of a glass inner cylinder surrounded by a glass water jacket. Water flows through the jacket at a constant rate controlled by a regulator at the tap. Air bubbles in the water, which might affect intensity measurements, are eliminated by an extractor shown at point $\mathrm{G}$ in figure 1 .

6. Pumps. The two main vacuum lines shown in figure 2 connect with independent pumping systems. The left-hand line goes to a trap, single stage oil diffusion pump and forepump while the right-hand line goes only to a trap and mechanical pump. The diffusion pump was used in these investigations because a wide variation in conditions was to be studied. 


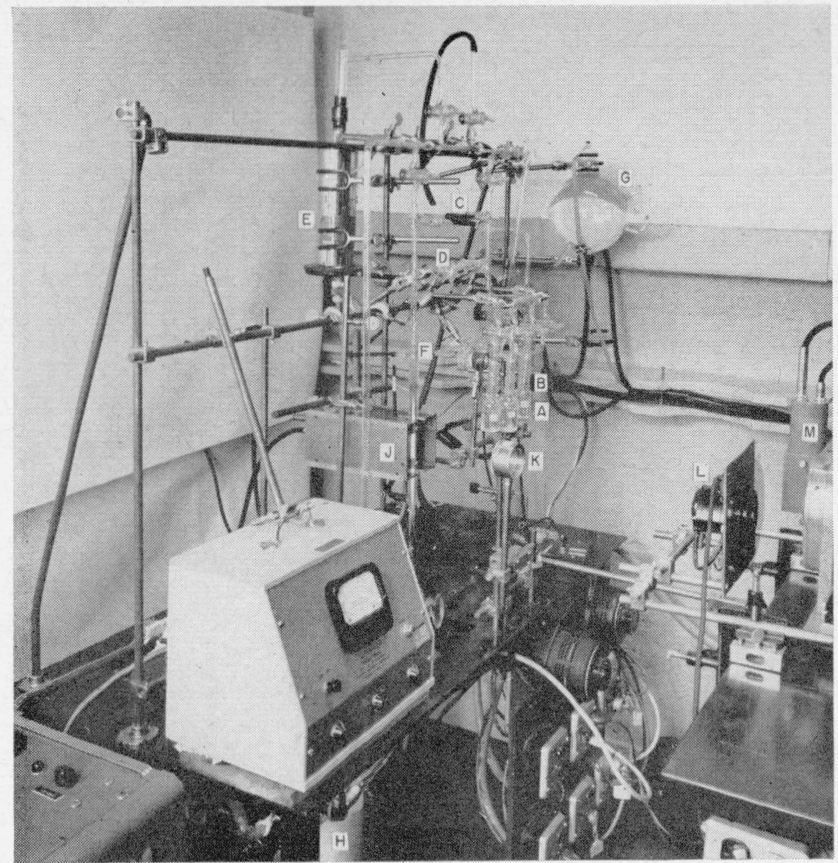

Figure 1. Flow system for H-D analysis.

A, Sample bottles; B, sample connectors; C, metal leak valve; D, glass capillary $\mathrm{E}$, pressure gage; $\mathrm{F}$, discharge tube; $\mathrm{G}$, bubble extractor; $H$, trap; J, shield for high-frequency source; $K$, lens; L, chopper; $M$, photomultiplier tube.

\subsection{High-Frequency Source}

The energy necessary to excite the spectrum of the sample was provided by a commercial 150-Mc $150-w$ oscillator. The energy is carried through a radio-frequency cable, which terminates in a tunable quarter-wavelength tank circuit with antennas held near the discharge tube. This terminal circuit is shown diagramatically in figure 2 . A radio-frequency shield (point $J$ in fig. 1) cuts down stray radiation, which might affect other electronic equipment.

\section{2 \\ 2.3. Monochromator}

The apparatus used to analyze the spectrum consists of a high-resolution grating monochromator with a photomultiplier detector and associated amplifier and recorder. ${ }^{3}$ A detailed discussion of the original monochromator is given by Fastie [6].

The plane diffraction grating used in the monochromator is 3 by 3 inches and is ruled with 30,000 lines per inch; the instrument has a practical resolving power $(\lambda / \Delta \lambda)$ of 55,000 . This resolution is sufficient to observe some of the fine structure splitting of $\mathrm{H}_{\alpha}$ and $\mathrm{D}_{\alpha}$ lines. The choice of optimum resolving power is governed by two considerations: it must be sufficient to resolve the lines to be analyzed

3 This equipment was on field trial loan to the National Bureau of Standards rom the Research Division of the Leeds \& Northrup Co.

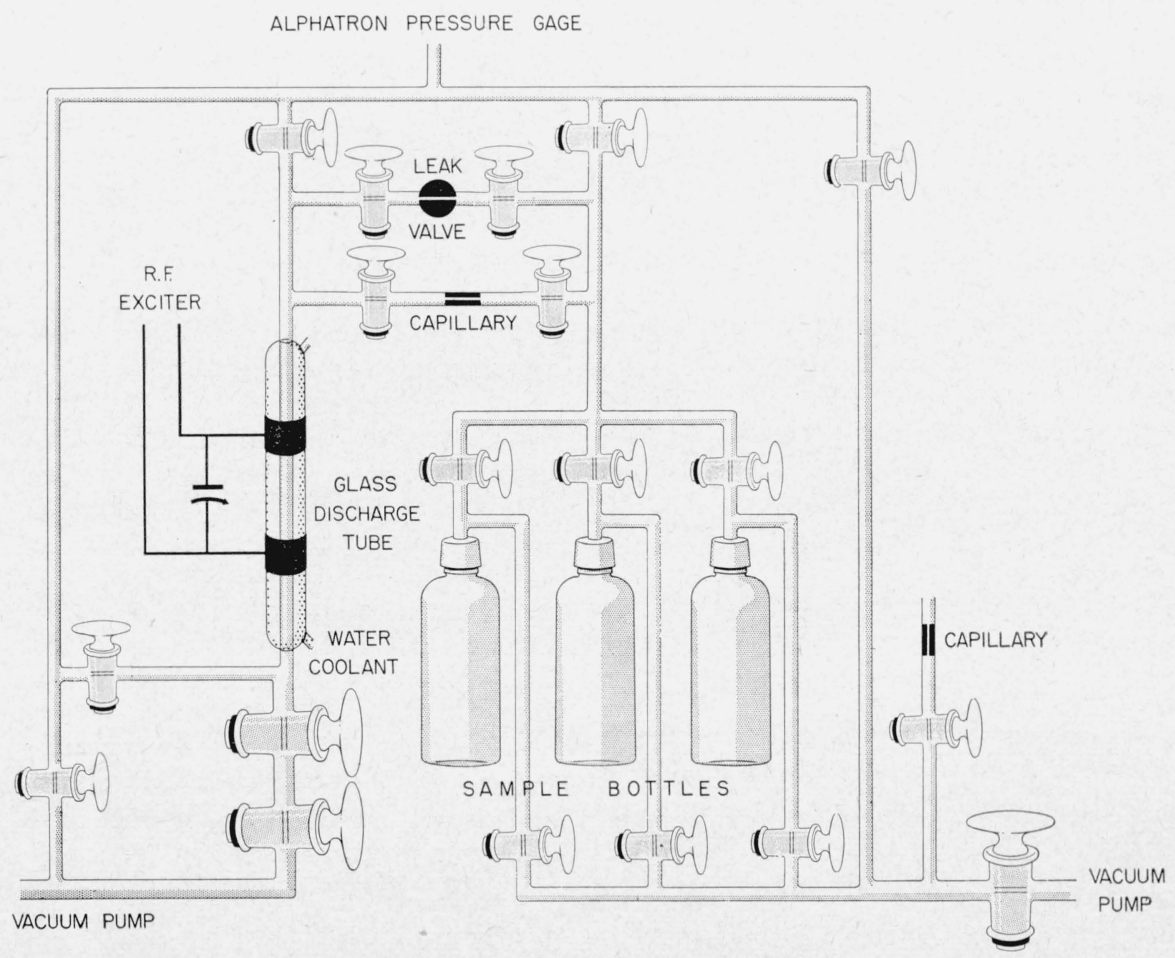

Figure 2. Schematic diagram of flow system. 

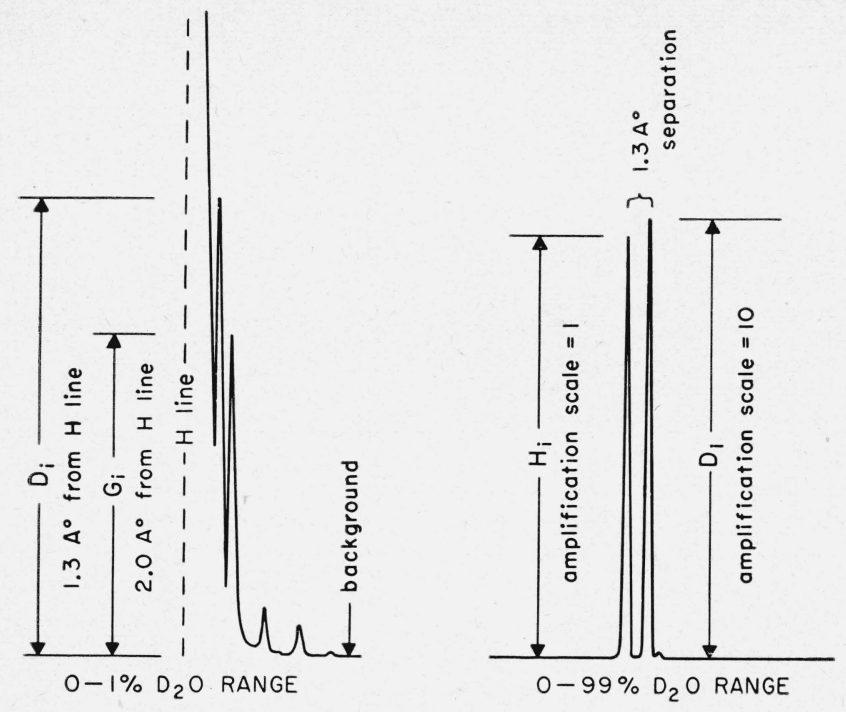

Figure 3. Method of measuring intensities $\left(\mathrm{H}_{\mathrm{i}}, \mathrm{D}_{\mathrm{i}}, \mathrm{G}_{\mathrm{i}}\right)$.

Height of $\mathrm{H}$ line $\left(\mathrm{H}_{\mathrm{i}}\right)$ is approximately 500 times that of $\mathrm{H}$ ghost line $\left(\mathrm{G}_{\mathrm{i}}\right)$. The zero line is arbitrarily taken $6.6 \mathrm{~A}$ from the $\mathrm{H}$ line, and intensities are measured as distances above the zero line. From left to right, traces are of 0.4 -percent and 10 percent $\mathrm{D}_{2} \mathrm{O}$ samples, respectively.

and at the same time be low enough to allow for the integrated intensity of a line to be approximated by the peak height of that line. The resolving power was varied by varying the width of the entrance and exit slits until the $\beta$ line of deuterium could be resolved in a normal water discharge $(\mathrm{D} / \mathrm{H}=0.00015)$ [7]. Figure 3 shows the $\mathrm{H}, \mathrm{D}$, and $\mathrm{H}$ ghost lines resolved, and indicates, on the basis of the half width of the line, a resolving power of 20,000 . This resolving power proved suitable for subsequent studies.

The first Rowland ghost of the $\beta$ line of hydrogen was spaced about $2.0 \mathrm{~A}$ from the line and was approximately one five-hundredths as intense. The $\beta$ line of deuterium appears between the $\mathrm{H}$ line and its first ghost. 'The ratio of ghost intensity to line intensity is a function of the optics of the system only, and under conditions of fixed optics may be taken as a constant. For low deuterium concentrations the ratio between the deuterium line and the $\mathrm{H}$ ghost is a fixed multiple of the ratio between the D and $\mathrm{H}$ lines. This fact proves useful in allowing comparison to be made between signals taken at the same scale of amplification, the calibration in this range being independent of the ratio of amplification for different scales.

\subsection{Power Supply, Amplifier, and Recorder}

A chopper before the entrance slit of the monochromator converts the input signal to $60 \mathrm{cps}$. This signal is fed into a narrow band-pass synchronous amplifier, the output of which is recorded by a pen on 10-inch chart paper. The recorder has a response time of 1 second. The power supply for the photomultiplier is continuously variable from 500 to $1,300 \mathrm{v}$. By using the photomultiplier with a sensitive linear a-c amplifier, which has an accurate amplification factor ranging from 2 to 800 , very small signals can be observed.

\section{Experimental Results}

The primary purpose of this study was to determine the effects of numerous interrelated variables on the speed, accuracy, and sensitivity of the method. The variables include pressure in the flow system, flow rate, sample size, solute composition of the sample, temperature, and oscillator characteristics. These variables will be considered in detail. The percentage change in ratio per unit change in variable was computed for each operating curve and can be used to determine how closely each variable must be controlled to achieve a desired precision (see table 7).

The methods of measuring intensity ratios for the 0 - to 1-percent $\mathrm{D}_{2} \mathrm{O}$ range and the 1- to 99-percent $\mathrm{D}_{2} \mathrm{O}$ range are shown in figure 3 . As previously discussed, the deuterium to ghost ratio is used instead of the deuterium to hydrogen ratio in the 0 - to 1 percent range. In the 1 - to 99 -percent range the $\mathrm{D}$ and $\mathrm{H}$ lines were measured directly at a lower amplification. In both concentration ranges the baseline, or background, is somewhat arbitrary and is taken at a fixed distance from the deuterium peak. This causes no error in the final measurement because the calibration is made in the same manner as the measurement.

\subsection{Contamination by a Previous Sample}

The speed with which a measurement can be taken is largely dependent on the time required to clean the system of one sample and saturate it with another so that a constant ratio is obtained. Metal parts are troublesome, but the metal leak valve usually was employed to gain fine pressure control in spite of its tendency to retain water with which it has previously been in contact.

Figure 4 shows a series of experiments under extreme conditions in which a pure water sample was run and then switched to commercial heavy water. Curve $a$ shows the effect, under the slowest conditions, of using the metal leak valve with no intermediate pumping or flushing. Curve $b$ shows the effect of using a glass capillary tube and a glass stopcock for pressure control with no intermediate pumping or flushing. For routine measurement the capillary tube and stopeock were used under the following conditions. The system was pumped with and without sample between extreme pressures in the ratio of at least 15 to 1 . These changes were made rapidly for approximately $2 \mathrm{~min}$, and then the pressure was stabilized to $400 \mu$. The effect of contamination by the previous sample was thereby reduced to that shown in curve $c$.

These curves show that an all-glass system, with intermediate flushing, most quickly reduces contamination. Even with an extreme change in concentration, equilibrium is reached to within 1 percent in 


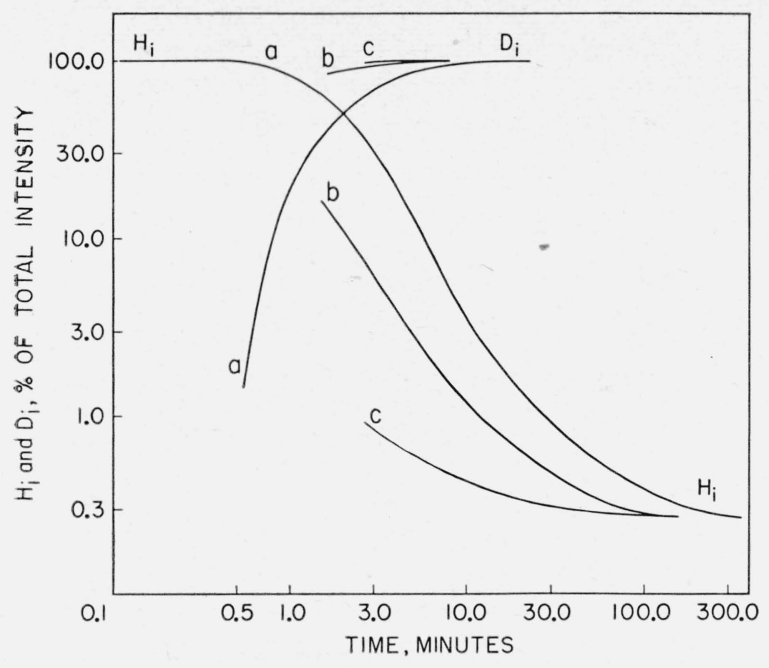

Figure 4. Residual contamination.

Pressure equals $400 \mu$. $a$, Metal leak valve, with no intermediate pumping or flushing between samples; $b$, glass stopcock, with no intermediate pumping or flushing; $c$, glass stopcock, with intermediate pumping and flushing.

less than $3 \mathrm{~min}$ and complete equilibrium in approximately $1 \mathrm{hr}$. The flow system shown in figure 2 was designed for maximum variability, but for routine use, a much simpler system is advantageous. Also the elimination of side projections should reduce the time to remove the previous sample.

\subsection{Pressure}

The operating pressure in the discharge tube has an effect on the intensity ratio, especially in the 0 - to 1-percent $\mathrm{D}_{2} \mathrm{O}$ range (see fig. 5). Flow rate was not held constant, so actually the traces show ratio versus a combination of pressure and flow rate at constant pumping speed as determined by settings of the metal leak valve and the speed of the pump. The flow rate in milligrams per minute decreased from 0.011 at a pressure of $900 \mu$ to 0.0023 at $400 \mu$ and 0.001 at $200 \mu$. The pressure gage used had the disadvantage of large metal surfaces, resulting in appreciable delay in removing traces of previous samples, an effect that is particularly undesirable when the concentration is being changed frequently. Therefore, the gage was isolated from the system after initial pressure setting and during the course of most intensity-ratio measurements. The disadvantage of not taking continuous pressure readings was overcome by using the discharge length as a pressure indicator because it is a sensitive function thereof. Although this variation could not be used for absolute measurement of pressure, it provided a good check on the constancy and reproducibility of pressure and flow conditions.

Intensity as a function of pressure was investigated at various concentrations, and the results are shown in figure 6 . The curves are quite similar at all concentrations. An operating pressure of approximately $400 \mu$ was chosen for routine use because it makes use of maximum intensity and the flattest portion of the

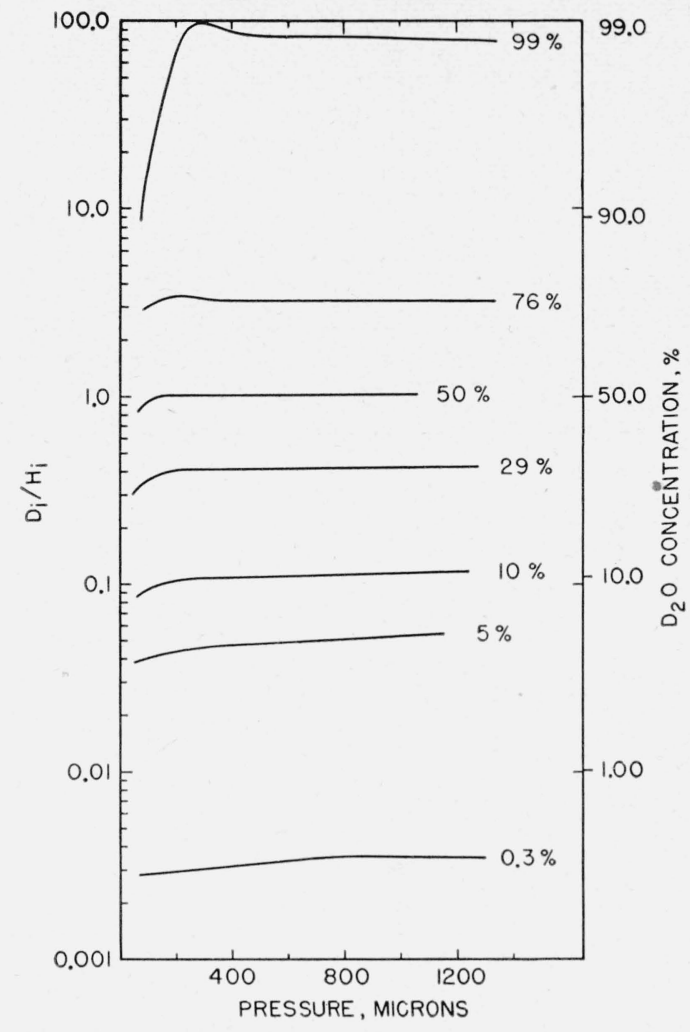

Figure 5. Intensity ratio versus pressure-seven samples at various concentrations.

The calibrated concentration of each sample by weighing is given at end of each trace.

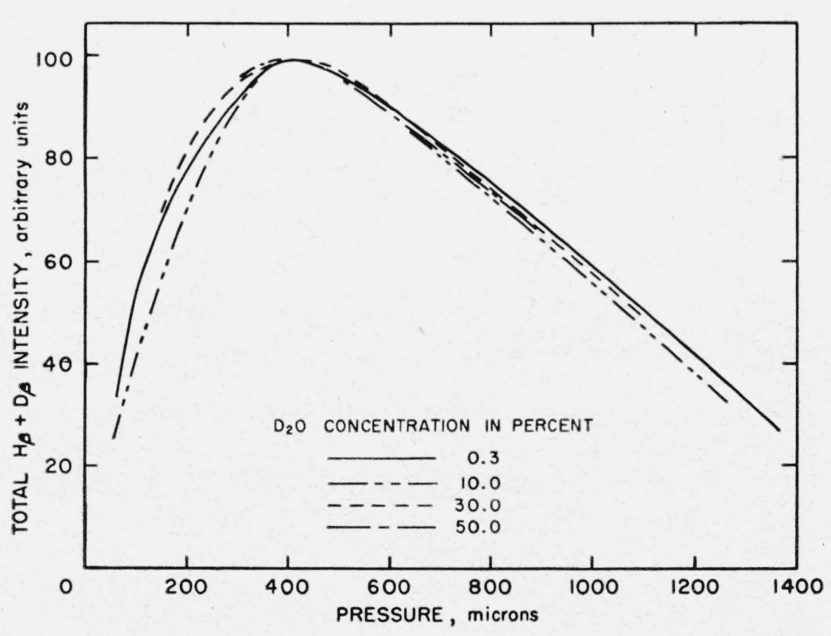

FiguRe 6. Total $\mathrm{H}_{\beta}+\mathrm{D}_{\beta}$ intensity versus pressure at various concentrations.

intensity versus pressure curve. It also occurs at regions of the ratio versus pressure curves that are reasonably flat. The percentage change of ratio per unit change in pressure at $400 \mu$ as computed from figure 5 is 0.020 percent per micron. This means that the pressure must be held to $\pm 5 \mu$ to achieve a precision of \pm 0.1 percent. 


\subsection{Fractionation}

At $20^{\circ} \mathrm{C}$ there is a difference of $2.3 \mathrm{~mm}$ of mercury between the vapor pressure of $\mathrm{H}_{2} \mathrm{O}$ and $\mathrm{D}_{2} \mathrm{O}$, with HDO having an intermediate pressure [7]. Thus a sample that is being evaporated will begin to concentrate deuterium. To check on the error to be expected from this effect, a $0.5-\mathrm{ml}$ sample was run continuously to dryness, with frequent checks made on the $\mathrm{D} / \mathrm{H}$ ratio. The results at an operating pressure of $200 \mu$ are shown in figure 7 . From this curve the minimum sample size can be computed for a given flow rate and allowable error. This is shown in detail in section 5 .

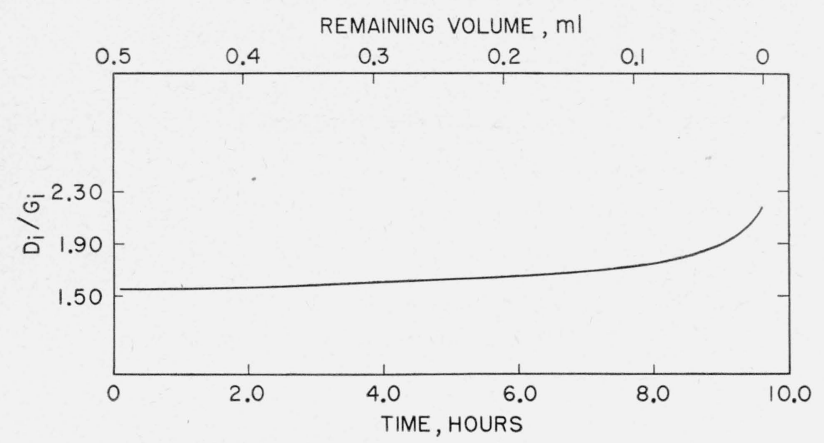

Figure 7. Fractionation effect.

Flow was continuous at $0.063 \mathrm{ml} / \mathrm{hr} . \mathrm{D}_{\mathrm{i}} / \mathrm{G}_{\mathbf{i}}$ scale is greatly expanded.

\subsection{Temperature}

The ratio of the vapor pressure of $\mathrm{H}_{2} \mathrm{O}, \mathrm{D}_{2} \mathrm{O}$, and HDO changes with temperature, so that some error might be expected from variation of sample temperature. To study this effect, sample bottles were immersed in a constant-temperature bath during these determinations. Table 1 shows the results obtained at temperatures ranging from $0.4^{\circ}$ to $25.8^{\circ}$ C. From this table the percentage change in ratio per unit change in sample temperature was computed to be 0.15 percent per deg $\mathrm{C}$.

TABLE 1. Intensity ratio versus sample temperature Pressure equals $500 \mu$.

\begin{tabular}{|c|c|c|}
\hline Sample & $\begin{array}{c}\text { Tempera- } \\
\text { ture }\end{array}$ & $\begin{array}{l}\text { Ratio } \\
\mathrm{D}_{\mathrm{i}} / \mathrm{H}_{\mathrm{i}}\end{array}$ \\
\hline $\begin{array}{l}\mathrm{S}-4 \ldots \ldots \ldots \\
\mathrm{S}-9 \ldots \ldots\end{array}$ & $\left\{\begin{array}{r}{ }^{\circ} C \\
4.0 \\
25.8 \\
0.4 \\
3.0 \\
17.0 \\
22.0\end{array}\right.$ & $\begin{array}{r}0.3895 \\
.3965 \\
.0454 \\
.0452 \\
.0466 \\
.0470\end{array}$ \\
\hline
\end{tabular}

\subsection{Flow-Rate}

Flow rate affects the $\mathrm{D} / \mathrm{H}$ ratio, the rate of fractionation, and the size of the smallest sample measurable. It is a function of pressure, the geometry of the flow system, and the speed of the pump. Table 2 gives data obtained for $\mathrm{D}_{1} / \mathrm{H}_{1}$ ratio as a function of the flow rate at constant pressure. This table shows that $\mathrm{D}_{1} / \mathrm{H}_{1}$ decreases with decreased flow rate and indicates that at least part of the effect of change of pressure (fig. 5) is caused by the reduced flow rate at lower pressures. The percentage change of ratio per unit change of flow rate computed from table 2 is 0.5 percent per gram a minute.

\section{TABLE 2. Intensity ratio versus flow rate}

Pressure equals $400 \mu$. Flow rate obtained by weighing sample before and after flow.

\begin{tabular}{|c|c|}
\hline Flow & $\begin{array}{c}\text { Ratio } \\
\mathrm{D}_{\mathrm{i}} / \mathrm{H}_{\mathrm{i}}\end{array}$ \\
\cline { 2 - 2 } & \\
\cline { 1 - 2 } g/min & \\
0.01125 & 0.899 \\
.00983 & .894 \\
.00331 & .857 \\
\hline
\end{tabular}

\subsection{Oscillator and Discharge Characteristics}

The discharge characteristics can be varied by changes in oscillator plate current, antenna tuning, position of electrodes with respect to the tube, and the temperature of the cooling stream in the jacket of the discharge tube. Plate current is variable between 100 and $200 \mathrm{ma}$, and the tuning is adjusted by the tuning capacitor in figure 2 as well as by the position of the radio-frequency shield and electrodes. The radio-frequency shield and electrodes were placed to obtain maximum intensity, and the tuning capacitor was varied to give a range of discharge lengths. Ratio of $\mathrm{D}_{1} / \mathrm{H}_{1}$ as a function of discharge length is shown in table 3 . The effect on $\mathrm{D}_{1} / \mathrm{H}_{1}$ of changing. the oscillator plate current is shown in table 4 . It is seen that there is no appreciable effect of the discharge length or plate current on the measured ratio. The temperature of the cooling stream was varied by changing the water flow rate through the discharge-tube jacket. $D_{1} / H_{1}$ varied less than 1 percent over the extreme range of temperature from a stream of the coldest water available from the tap (approximately $18^{\circ} \mathrm{C}$ ) to no cooling (greater than $\left.200^{\circ} \mathrm{C}\right)$.

TABLE 3. Intensity ratio versus percentage maximum discharge length

Pressure equals $500 \mu$

\begin{tabular}{|c|c|c|}
\hline Sample & $\begin{array}{l}\text { Percentage of } \\
\text { maximum dis- } \\
\text { charge length }\end{array}$ & $\begin{array}{l}\text { Ratio } \\
D_{i} / H_{i}\end{array}$ \\
\hline S-9................... & $\left\{\begin{array}{c}100 \\
88.6 \\
73.8 \\
49.4 \\
100 \\
98 \\
91.8 \\
82.7 \\
75.1 \\
64.7 \\
52.0 \\
49.0\end{array}\right.$ & $\begin{array}{l}4.71 \\
4.78 \\
4.85 \\
4.48 \\
49.74 \\
49.5 \\
49.71 \\
49.79 \\
49.97 \\
50.17 \\
50.04 \\
49.79\end{array}$ \\
\hline
\end{tabular}


TABLE 4. Intensity ratio versus oscillator plate current

Pressure equals $500 \mu$

\begin{tabular}{|c|c|c|}
\hline 7 & $\begin{array}{l}\text { Plate } \\
\text { current }\end{array}$ & $\begin{array}{l}\text { Ratio } \\
\mathrm{D}_{\mathrm{i}} / \mathrm{H}_{\mathrm{i}}\end{array}$ \\
\hline $\begin{array}{l}\mathrm{S}-9 \ldots \ldots \ldots \\
\mathrm{S}-12 \ldots \ldots\end{array}$ & $\left\{\begin{array}{c}m a \\
100 \\
122 \\
140 \\
175 \\
190 \\
100 \\
125 \\
130 \\
150 \\
185 \\
200 \\
210\end{array}\right.$ & $\begin{array}{r}0.0503 \\
.0499 \\
.0491 \\
.0491 \\
.0490 \\
1.015 \\
1.016 \\
1.013 \\
1.015 \\
1.012 \\
1.012 \\
1.012\end{array}$ \\
\hline
\end{tabular}

\subsection{Solute Composition}

As the optical spectroscopic method of analysis may be extended for use with many aqueous solutions, preliminary investigation was made of the variation of $\mathrm{D}_{1} / \dot{\mathrm{H}}_{1}$ ratio with the amount of solids dissolved in the sample. This test was made with $\mathrm{NaCl}$. With concentrations of 0 percent, 1 percent, 10 percent, and a saturated solution, no variation of $\mathrm{D}_{\mathrm{i}} / \mathrm{H}_{1}$ was found within the experimental error.

\section{Calibration Curves, Precision, and Repro- ducibility}

Calibration curves were necessary to achieve the highest accuracy. Figure 8 shows the 0- to 1-percent $\mathrm{D}_{2} \mathrm{O}$ range and figure 9 the 1 - to 80 -percent $\mathrm{D}_{2} \mathrm{O}$ range. ${ }^{4}$ Samples were made by mixing portions of distilled water and commercial $\mathrm{D}_{2} \mathrm{O}(99.8 \%)$ that had been weighed to an accuracy of $0.1 \mathrm{mg}$.

Table 5 gives examples of the isotope content expressed, for comparison, in ratio and in percent, and shows the precision obtained under optimum conditions.

TABLE 5. Comparison of ratio method and percentage concentration method of expressing isotope content

\begin{tabular}{|c|c|c|c|c|c|}
\hline $\begin{array}{l}\text { Ratio } \\
\mathrm{D} / \mathrm{H}\end{array}$ & $\begin{array}{l}\text { Standard } \\
\text { deviation } \\
\text { of average } \\
\text { of ratio a }\end{array}$ & $\begin{array}{c}\text { Coefficient } \\
\text { of } \\
\text { variation } \\
\text { of average b }\end{array}$ & $\begin{array}{c}\begin{array}{c}\text { Deuterium } \\
\text { concentra- } \\
\text { tion } \\
100 \mathrm{D} / \mathrm{D}+\mathrm{H}\end{array}\end{array}$ & $\begin{array}{c}\text { Standard } \\
\text { deviation of } \\
\text { average of } \\
\text { concentra- } \\
\text { tion a }\end{array}$ & $\begin{array}{l}\text { Coefficient } \\
\text { of } \\
\text { variation of } \\
\text { average b }\end{array}$ \\
\hline $\begin{array}{r}500 \\
100 \\
10 \\
1 \\
.1 \\
.01 \\
.001 \\
.0001\end{array}$ & $\begin{array}{l}5.0 \\
0.1 \\
.01 \\
.001 \\
.0001 \\
.00001 \\
.000007 \\
.000002\end{array}$ & $\begin{array}{r}1.0 \\
0.1 \\
.1 \\
.1 \\
.1 \\
.1 \\
.7 \\
2.0\end{array}$ & $\begin{array}{c}\% \\
99.8 \\
99.0 \\
90.9 \\
50.0 \\
9.09 \\
0.99 \\
.100 \\
.01\end{array}$ & $\begin{array}{l}0.002 \\
.001 \\
.01 \\
.25 \\
.01 \\
.001 \\
.0007 \\
.0002\end{array}$ & $\begin{array}{l}0.002 \\
.001 \\
.01 \\
.05 \\
.01 \\
.1 \\
.7 \\
2.0\end{array}$ \\
\hline
\end{tabular}

a Based on a set of 10 readings.

b Standard deviation of average, expressed in percent.

4 Calibration curves were taken on samples up to 99.8 percent of $\mathrm{D}_{2} \mathrm{O}$ (commercially a vailable), but no extensive measurements were made in the high-concentration range. The analysis in this range differs
only in the method of preparing standard samples.

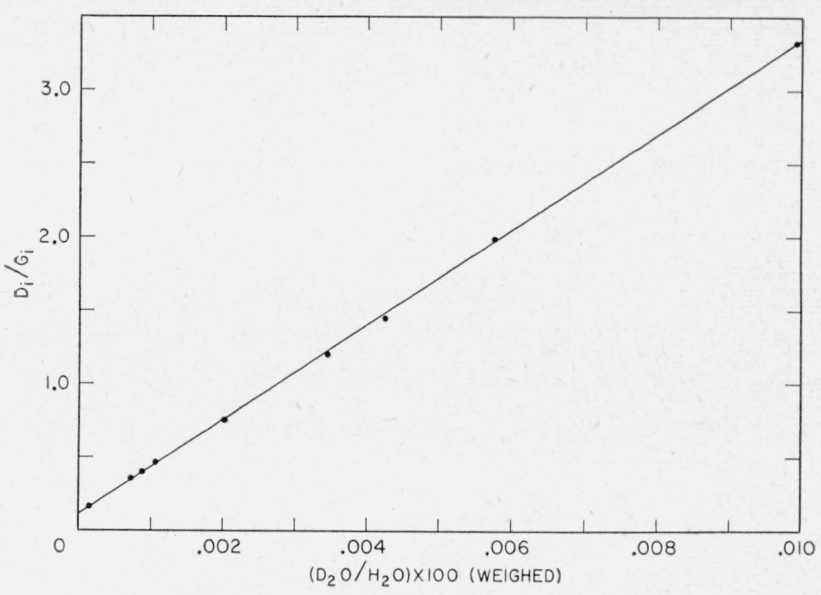

Figure 8. Calibration curve for 0 - to 1-percent $\mathrm{D}_{2} \mathrm{O}$ concentration range.

Samples were made up by weighing.

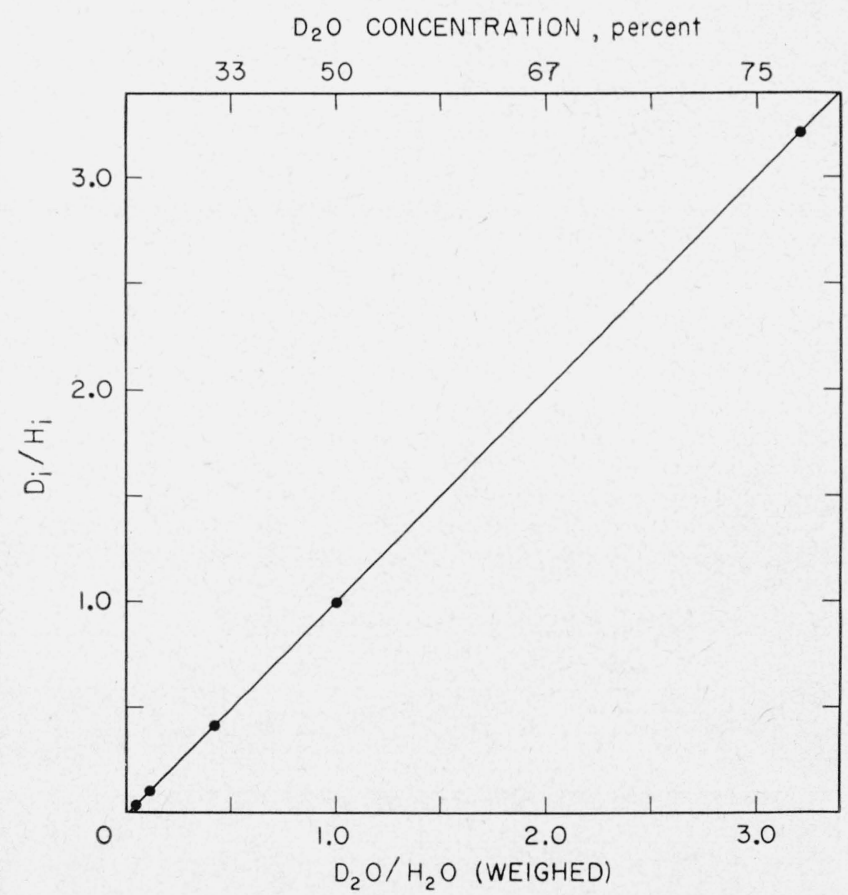

Figure 9. Calibration curve for 1 - to 80-percent $\mathrm{D}_{2} \mathrm{O}$ concentration range.

80- to 99-percent portion of the curve is omitted because of the extended scale. Samples were made up by weighing.

Reproducibility was measured on a 21-percent $\mathrm{D}_{2} \mathrm{O}$ sample and a 0.2 -percent $\mathrm{D}_{2} \mathrm{O}$ sample. Measurements were taken at varying time intervals, and in some cases with major changes taking place during the interval, both in the apparatus and in the concentration ratios. Results are shown in figure 10 for 4 portions of the 21-percent sample. 


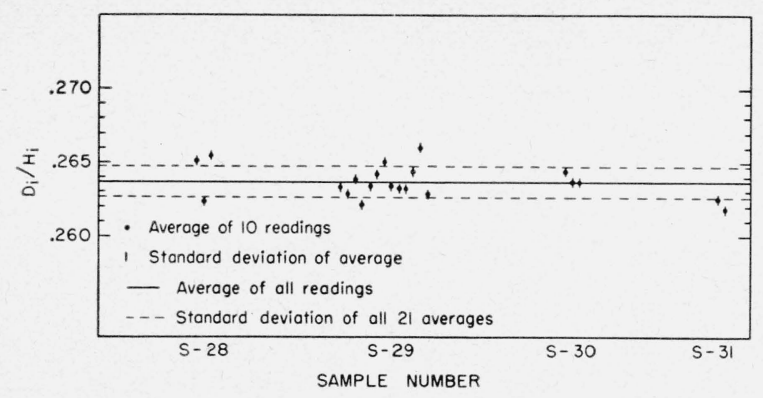

Figure 10. Precision and reproducibility for 21-percent $\mathrm{D}_{2} \mathrm{O}$ samples.

The data were taken over a period of 3 months, and dates are given below, reading from left to right on figure 10 .

\begin{tabular}{|c|c|c|c|c|}
\hline Sample & Date & Sample & & ate \\
\hline $\mathrm{S}-28$ & $\left\{\begin{array}{lr}\text { Dec. } & 9,1952 \\
\text { Dec. } & 9,1952 \\
\text { Dec. } & 23,1952 \\
\text { Dec. } & 1,1952 \\
\text { Dec. } & 1,1952 \\
\text { Dec. } & 2,1952 \\
\text { Dec. } & 2,1952 \\
\text { Dec. } & 3,1952 \\
\text { Dec. } & 3,1952 \\
\text { Dec. } & 4,1952 \\
\text { Dec. } & 5,1952 \\
\text { Dec. } & 5,1952 \\
\text { Dec. } & 5,1952 \\
\text { Dec. } & 5,1952 \\
\text { Dec. } & 22,1952 \\
\text { Feb. } & 25,1953\end{array}\right.$ & $\begin{array}{l}\mathrm{S}-30 \\
\mathrm{~S}-31\end{array}$ & $\begin{array}{l}\left\{\begin{array}{l}\text { Dec. } \\
\text { Dec. } \\
\text { Dec. }\end{array}\right. \\
\left\{\begin{array}{l}\text { Dec. } \\
\text { Dec. }\end{array}\right.\end{array}$ & $\begin{array}{r}4,1952 \\
4,1952 \\
23,1952 \\
19,1952 \\
19,1952\end{array}$ \\
\hline
\end{tabular}

Each point shows the average of 10 readings, with the precision depicted as vertical spread. The grand average is a solid horizontal line, and the standard deviation computed directly from all 21 averages is shown by dotted lines on either side of the grand average. Thus the relation between precision and reproducibility at this stage of development can be seen at a glance. The results obtained for the 0.2-percent sample were similar. Data for it are listed in table 6 .

TABLE 6. Reproducibility of intensity ratio for a 0.2-percent $\mathrm{D}_{2} \mathrm{O}$ sample over a 1-month period.

Each ratio is the average of 10 readings. Pressure equals $200 \mu$.

\begin{tabular}{|c|c|c|c|}
\hline Date, 1953 & $\mathrm{D}_{\mathrm{i}} / \mathrm{G}_{\mathrm{i}}^{\mathrm{a}}$ & Date, 1953 & $\mathrm{D}_{\mathrm{i}} / \mathrm{G}_{\mathrm{i}}{ }^{\mathrm{a}}$ \\
\hline $\begin{array}{l}\text { April } 28 \\
\text { May } 1 \ldots \\
\text { May } 2 \ldots \\
\text { May } 4 \ldots \\
\text { May } 7 \ldots \ldots \\
\quad \text { Do } \\
\quad \text { Do }\end{array}$ & $\begin{array}{l}0.760 \\
.737 \\
.736 \\
.733 \\
.729 \\
.724 \\
.744\end{array}$ & $\begin{array}{l}\text { May } 11 \\
\text { May } 15 \\
\text { May } 18 \\
\text { Do } \\
\text { May } 19 \\
\text { May } 20\end{array}$ & $\begin{array}{l}.753 \\
.740 \\
.769 \\
.754 \\
.765 \\
.753\end{array}$ \\
\hline $\begin{array}{r}\text { May } 8 \ldots \\
\text { Do }\end{array}$ & $\begin{array}{l}.751 \\
.743\end{array}$ & A verage... & 0.746 \\
\hline
\end{tabular}

s $\mathrm{G}_{\mathrm{i}}$ is the measured intensity of the ghost of the $\mathrm{H}$ line.

\section{Discussion}

The great number of variables that influence the measurement of $\mathrm{D} / \mathrm{H}$ ratios makes it impossible to be certain that the final operating conditions are in fact the optimum ones. Indeed, it is not necessary to assume that there is a unique set of optimum conditions for this analysis. The operating conditions chosen therefore are the "best set", based upon data available and the nature of the measurements to be performed. Some of the final data used to evaluate operating conditions are shown in table 7 . This table illustrates that there is no extreme problem in keeping the operating conditions constant enough so that the measurement can be made within the desired accuracy.

TABLE 7. Operating variables

\begin{tabular}{|c|c|c|}
\hline $\begin{array}{l}\text { Operating condition } \\
\text { varied }\end{array}$ & $\begin{array}{l}\text { Percentage change of } \\
\text { ratio per unit change } \\
\text { of variable }\end{array}$ & $\begin{array}{l}\text { Routine operating } \\
\text { conditions }\end{array}$ \\
\hline Sample temperature. & 0.15 percent per $\operatorname{deg} \mathrm{C}_{\ldots}$ & Room temperature. \\
\hline Pressure ........... & 0.020 percent per micron_ & 400 microns. \\
\hline Salt concentration & 0 percent per mole/liter & Any. \\
\hline Flow rate........... & 0.5 percent per $\mathrm{g} / \mathrm{min}$ & $\begin{array}{l}\text { Depending on sample } \\
\text { size and desired } \\
\text { speed of measure- } \\
\text { ment. }\end{array}$ \\
\hline Tuning & $\begin{array}{l}0 \text { percent per percentage } \\
\text { change in discharge } \\
\text { length. }\end{array}$ & $\begin{array}{l}\text { Maximum discharge } \\
\text { length. }\end{array}$ \\
\hline $\begin{array}{l}\text { Oscillator plate cur- } \\
\text { rent. }\end{array}$ & 0 percent per ma........ & $175 \mathrm{ma}$. \\
\hline $\begin{array}{l}\text { Discharge tube tem- } \\
\text { perature. }\end{array}$ & 0.005 percent per $\operatorname{deg} \mathrm{C}_{\ldots}$. & Room temperature. \\
\hline
\end{tabular}

Accessory factors enter into the choice of best conditions. The fractionation curve (fig. 7) can be represented as $R S^{k}=K$, where $R$ is the isotope ratio, $S$ is the sample size, and $k$ and $K$ are experimental constants. In differential form the fractionation curve can be represented as $d R / R=-(k / S) d S$, where the left-hand term represents the percentage change of ratio due to fractionation. Setting $d R / R$ equal to $e$, the maximum tolerable fractionation error, and realizing that $d S=-f \Delta t$, the flow-rate times the time increment, we arrive at the following expression for minimum sample size:

$$
S=\frac{0.068 f \Delta t}{e}
$$

The value of $k, 0.068$, was obtained from the data shown in figure 7 . As has been mentioned previously, flow-rate depends on operating pressure, flowgeometry, and pumping speed, and the time of measurement depends on the time required to clean the system of the previous sample and to equalize the pressure. Hence, sample size is some complex function of the major operating variables. Under normal conditions at a $400-\mu$ operating pressure the flow rate was $0.0023 \mathrm{ml} / \mathrm{min}$, and the time per determination was $20 \mathrm{~min}$. The minimum sample size is therefore $0.00313 / e$, or $0.3 \mathrm{ml}$, for a 1 -percent error. The absolute minimum sample size under present conditions involves an operating pressure of $200 \mu$ and a maximum error of 3 percent. - Under 
these conditions, a 7-min measurement is possible, and the minimum sample size is $0.02 \mathrm{ml}$.

The operating conditions that were found to be most suitable with the equipment described are shown in table 7 .

This study is not exhaustive, inasmuch as there are many combinations of variables that were not tried. In addition, no attempt was made to vary systematically such things as the oscillator frequency or discharge-tube geometry. A few preliminary experiments with a $2,240-\mathrm{Mc}$ oscillator indicate that a stable set of operating conditions can be set up at that frequency.

As pointed out in the beginning of this paper, the chief object of these studies was to determine how to minimize error, sample size, and time of determination. Of course, it is impossible to minimize all three factors at once. Highest precision requires many determinations per sample, hence a long time and large sample size. The minimum values attainable at the present stage of development and the maximum values obtained while minimizing the others are given as follows:

\begin{tabular}{|c|c|c|}
\hline Factor & Minimum & Maximum \\
\hline $\begin{array}{l}\text { Precision (coefficient of } \\
\text { variation of the aver- } \\
\text { age) } \\
\text { Sample size } \\
\text { Time per sample }\end{array}$ & $\begin{array}{l}0.1 \text { to } 2 \text { per- } \\
\text { cent. } \\
0.02 \mathrm{ml} \\
7 \mathrm{~min}\end{array}$ & $\begin{array}{c}3 \text { percent } \\
1 \mathrm{ml} \\
60 \mathrm{~min}\end{array}$ \\
\hline
\end{tabular}

With respect to precision and time per determination, the optical spectroscopic case compares favorably with other methods. It finds particular application where the water samples contain impurities. Whereas other methods require one or two stages of purification, the sample vapor can be analyzed directly by this method. This method appears to be considerably more rapid and, for similar accuracy, less expensive than other methods.

While it is not the function of this paper to discuss, in detail, applications of hydrogen-deuterium analysis, we shall review briefly in the following paragraphs some of the most important uses to which the optical spectroscopic method has been placed. The dilution technique for determining the total water content of materials involved in these uses is described in reference [3]. Essentially, it consists in dissolving or suspending a known amount of the material to be analyzed in a mixture of $\mathrm{D}_{2} \mathrm{O}$ and $\mathrm{H}_{2} \mathrm{O}$ and then determining spectroscopically the resulting change in the ratio of $\mathrm{D}_{2} \mathrm{O}$ to $\mathrm{H}_{2} \mathrm{O}$.

1. Determination of $\mathrm{D}_{2} \mathrm{O}$ content of blood. In this application the blood, serum, or plasma is placed in the sample bottle and the vapor analyzed in the usual manner. No prior preparation of the blood is necessary and high precision is obtainable. This technique finds application in the determination of total body water by $\mathrm{D}_{2} \mathrm{O}$ dilution and in the study of water exchange in capillary beds. Over 150 blood samples have been run, and no difficulty has been encountered in adapting the techniques to routine analysis.

2. Determination of water of hydration or water of crystallization. The crystal to be analyzed is dissolved in $\mathrm{D}_{2} \mathrm{O}$, and the final intensity ratio gives a measure of the $\mathrm{H}_{2} \mathrm{O}$ originally in the crystal. Several hydrates have been tried, and the results agree with other methods.

3. Determination of labile hydrogen. A weighed quantity of dry material containing labile hydrogen is dissolved in $\mathrm{D}_{2} \mathrm{O}$ and the resultant ratio measured. From the number of exchangeable hydrogen atoms per molecule, information about structure of the molecule is obtained.

The most extensive work has been done with blood, for which a brief description of the routine application follows.

Army Medical Service gave injections of $100 \mathrm{~g}$ of commercially pure $\mathrm{D}_{2} \mathrm{O}$ to several hemorrhagic fever patients and sampled blood at various time intervals. The serum samples were analyzed at the National Bureau of Standards to determine the total body water content of the patients. Seventy-three samples in the concentration range 0.029 to 0.425 percent gave precisions of the order of 0.7 -percent coefficient of variation of the average. Ten readings were taken per sample, using the metal leak valve for pressure control. The time per sample ranged between 25 and $55 \mathrm{~min}$, depending on stability of operating conditions.

Reference [8] gives details of a study of transcapillary exchange rates of $\mathrm{D}_{2} \mathrm{O}$ and thiocyanate in the forearm of man. A study has since been made of the exchange rates from the artery of one arm to the vein of the other. In this case only five readings were taken per sample and metal parts were eliminated, thus cutting the total time per sample down to $15 \mathrm{~min}$, plus data calculation time. The precision of measurement was of the order of 1.5percent coafficient of variation of the average for 17 samples in the concentration range 0.015 to 2.00 percent of $\mathrm{D}_{2} \mathrm{O}$.

\section{References}

[1] H. P. Broida and J. W. Moyer, Spectroscopic analysis of deuterium in hydrogen-deuterium mixtures, J. Opt. Soc. Am. 42, 37 (1952).

[2] H. P. Broida and G. H. Morgan, Optical spectrophotometric analysis of hydrogen-deuterium mixtures in presence of air, Anal. Chem. 24, 799 (1952).

[3] H. J. Morowitz and H. P. Broida, Rapid spectroscopic determination of total water content, Anal. Chem. 24, 1657 (1952).

[4] W. J. Youden, Statistical methods for chemists (John Wiley \& Sons, Inc., New York, N. Y., 1951).

[5] ASTM Manual on quality control of materials, Am. Soc. Testing Materials (Philadelphia, Pa., January 1951).

[6] William G. Fastie, A small plane grating monochromator, J. Opt. Soc. Am. 42, 641 (1952).

[7] I. Kirshenbaum, Physical properties and analysis of heavy water, p. 396 (McGraw-Hill Book Co., New York, N. Y., 1951).

[8] Edward' D. Freis, Thomas F. Higgins, and Harold J. Morowitz, Transcapillary exchange rates of deuterium oxide and thiocyanate in the forearm of man, J. Appl. Physiol. 5, 526 (1953).

Washington, November 25, 1953. 